\title{
Industrial agglomeration and product quality improvement of food enterprises: empirical analysis based on data from Chinese enterprises
}

\author{
Jiyuan $\mathrm{ZHENG}^{1}$ (D), Hao HU⿱一土丷
}

\begin{abstract}
This study utilized data on dairy enterprises, which are representative of China's food industry, to investigate the relationships and mechanisms between industrial agglomeration and the product quality of food enterprises. The results show that industrial agglomeration significantly improves the product quality of Chinese food enterprises. In general, the economic effect of China's food industry agglomeration is greater than that of excessive competition. The heterogeneity analysis showed that industrial agglomeration plays a more important role in promoting the product quality of non-state-owned enterprises and food enterprises in the eastern region than in state-owned enterprises and the central and western regions. Further mechanistic analysis showed that industrial agglomeration promotes food quality improvement by improving enterprise productivity and fixed cost input efficiency. Therefore, this study confirms that industrial agglomeration can be used as an external driving force for China's food quality improvement. On the basis of market mechanisms, through the guidance of the macro policy of industrial agglomeration, the external economies of the scale effect of agglomeration are of great significance for helping the food industry become high quality and high end.
\end{abstract}

Key words: industrial agglomeration; product quality; scale economy; empirical analysis.

Practical Application: This manuscript expand the application scope of industrial agglomeration theory and improves the research perspective of food quality and safety management.

\section{Introduction}

Food safety is related not only to people's health but also to industry. Since 2008, consumers' demand for high-quality food safety has increased annually. In 2015, the strictest food safety law in Chinese history was promulgated. In 2017, the 13th Five-Year National Food Safety Plan proposed adhering to the most stringent standards, the strictest supervision, the most severe punishment and the most serious accountability ever applied to the food industry and called for a comprehensive implementation of food safety strategies. In 2019, the "opinions of the CPC Central Committee and the State Council on deepening reform and strengthening food safety work" once again stressed that it is necessary to further strengthen food quality and safety and ensure "safety at the tip of the tongue" of the people. Currently, the overall trend in China's food quality and safety is good, but the situation is still grim. Food quality and safety management are still urgent social problems to be solved; they represent a challenge and hot spot in theoretical research and practical exploration and have attracted the attention of scholars in China and around the world.

In recent years, domestic and foreign scholars have carried out a significant amount of research on food quality and safety and formed a consensus. Food quality and safety problems are mainly caused by "potential hazards", such as microbial pathogens, human and animal symbiotic diseases, parasitic tissues, natural toxins and allergens, pesticide and veterinary drug residues, and heavy metals, that exceed the standard levels (World Health Organization, 2002); for deep-seated reasons, food quality and safety problems are mainly attributed to the presence of incorrect information in the transaction process. Two root causes of the high transaction costs of addressing information asymmetry problems are discussed (Zhong \& Chen, 2014). Although many studies assess food quality and safety from the perspectives of the supply chain structure, industrial structure and regulatory system, these factors ultimately affect food quality and safety indirectly through the behavior of producers and operators. Food enterprises' motivation for quality and safety control can be divided into two categories: external motivation, such as meeting consumer demand, expanding market share and meeting the requirements of laws and regulations, and internal motivation, which is mainly related to reducing costs and increasing profits (Yapp \& Fairman, 2006). For several food quality and safety incidents, the results show that excessive cost reduction is the main cause of quality and safety problems. Therefore, reasonable cost reduction has become one of the core ways to address food quality and safety problems. Several studies have shown that industrial agglomeration, as a localized production mode, can promote the flow and sharing of factors among enterprises through the connected production network and can reduce the transaction costs among enterprises (Melo et al., 2009). The research results of some scholars show that industrial 
agglomeration has a positive and significant impact on improving product quality (Liu et al., 2016). Su et al. (2018) showed that industry agglomeration significantly improved the quality of corporate products. The mechanism verification results show that industrial agglomeration promotes products by improving the efficiency of enterprises' fixed cost investment. The research proves that industrial agglomeration can be used as an internal driving force of China's product quality improvement. Thus, this paper starts from the perspective of industrial agglomeration, based on the data of Chinese dairy enterprises, fully considers the internal logic and mechanism of industrial agglomeration and dairy product quality improvement, and uses a panel data model to empirically analyze and test the internal relationship. This analysis of food quality improvement based on the perspective of industrial agglomeration will aid in the analysis of the current problems of food quality and safety in China from the perspective of industrial policy to provide a reliable theoretical basis for future policy design.

\section{Theoretical mechanism and research hypothesis}

The impact of industrial agglomeration on product quality has been a focus and hot spot of research in recent years. Through the analysis and elaboration in the introduction section, based on the theory of the agglomeration effect, the mechanisms by which industrial agglomeration promotes food quality were theoretically deduced, and the intermediary variables between the two factors were determined, which provided a theoretical basis for the empirical research presented in this paper.

\subsection{Theoretical framework}

Based on the theoretical framework for product quality heterogeneity constructed by Hallak \& Sivadasan (2008), Khandelwal et al. (2013), this section theoretically deduces the determinants of the product quality of food enterprises and explores the mechanism by which industrial agglomeration affects food quality as an intermediary variable, which provides a theoretical basis for the empirical study.

\section{Consumer demand}

The CES utility function of consumers is set as follows (Formula 1):

$U=\left\{\int_{g \in \Omega}[\lambda(g) q(g)]^{(\sigma-1) / \sigma} d g\right\}^{\sigma /(\sigma-1)}$

where $g$ is the final product; $\Omega$ is the product category set that consumers can buy; $\lambda(g)$ is the quality level of product $g ; q(g)$ is the quantity of product $g$ consumed by consumers; and $\sigma(\sigma>1)$ is the substitution elasticity between any two products. Therefore, the price index $\mathrm{P}$ can be expressed as Formula 2

$$
P=\int_{g \in \Omega} p(g)^{1-\sigma} \lambda(g)^{\sigma-1} d g
$$

Under the given budget constraints, according to the utility maximization equation of consumers, the optimal solution can be obtained as follows:

$q(g)=\lambda(g)^{\sigma-1} p(g)^{-\sigma} D / P$

where D is consumer spending. Formula 3 shows that in the vertically differentiated market, consumers' preference for products depends not only on the price but also on the quality of products.

\section{Market supply}

Assuming that the production cost of an enterprise includes the fixed cost and variable cost, the marginal production cost (MC) and fixed production cost (F) can be expressed as follows:

$M C(\lambda, \varphi)=(c / \varphi) \lambda^{\gamma}, F(\lambda, \varepsilon)=F_{0}(f / \varepsilon) \lambda^{\delta}$

where ${ }^{\varphi}$ and $\varepsilon$ are the productivity and fixed cost input efficiency, respectively; $\lambda$ represents the food quality level; $\gamma \gamma>0$ and $\delta \delta>0$ are the quality elasticity of the marginal cost and fixed cost, respectively; and $c$ and $f$ are constants, which are unit prices of the variable cost input and fixed cost input, respectively. The higher the productivity is, the lower the variable cost; the higher the efficiency of the fixed cost is, the lower the fixed cost. Specifically, $\varphi$ is used to describe marginal cost heterogeneity; $\varepsilon$ is used to describe fixed cost heterogeneity, which reflects the ability of enterprises to produce high-quality products at the lowest possible fixed cost (Gervais, 2015), and there are significant differences in the efficiency of fixed cost investment (Zhang et al., 2003).

\section{Equilibrium}

Assuming that all enterprises choose the optimal production decision according to the principle of pursuing their own profit maximization, by combining Formula 3 of the demand function and Formula 4 of the cost function, the expression of the product quality level produced by enterprises can be obtained as follows:

$\lambda(\varphi, \varepsilon)=\left[\frac{1-\gamma}{\delta}\left(\frac{\sigma-1}{\sigma}\right)^{\sigma}\left(\frac{\varphi}{c}\right)^{\sigma-1} \frac{\varepsilon}{f} \frac{D}{P}\right]^{\frac{1}{\delta^{\prime}}}$

where $\delta^{\prime}=\delta-1-\gamma \sigma-1>0,0<\gamma\langle 1, \delta\rangle \delta^{\prime}$. From Formula 5, the product quality level of an enterprise is endogenously determined by factors such as enterprise productivity and fixed cost input efficiency. Furthermore, the first derivative of $\varphi$ and $\varepsilon$ is obtained:

$$
\begin{aligned}
& \frac{\partial \lambda(\varphi, \varepsilon)}{\partial \varphi}=\frac{1}{\delta^{\prime}}\left[\frac{1-\gamma}{\delta}\left(\frac{\sigma-1}{\sigma}\right)^{\sigma}\left(\frac{\varphi}{c}\right)^{\sigma-1} \frac{\varepsilon}{f} \frac{D}{P}\right]^{\frac{1}{\delta^{\prime}}-1} \frac{\sigma-1}{c} \frac{1-\gamma}{\delta}\left(\frac{\sigma-1}{\sigma}\right)^{\sigma}\left(\frac{\varphi}{c}\right)^{\sigma-2} \frac{\varepsilon}{f} \frac{D}{P}>0 \\
& \frac{\partial \lambda(\varphi, \varepsilon)}{\partial \varepsilon}=\frac{1}{\delta^{\prime}}\left[\frac{1-\gamma}{\delta}\left(\frac{\sigma-1}{\sigma}\right)^{\sigma}\left(\frac{\varphi}{c}\right)^{\sigma-1} \frac{\varepsilon}{f} \frac{D}{P}\right]^{\frac{1}{\delta^{\prime}}-1} \frac{1}{f} \frac{1-\gamma}{\delta}\left(\frac{\sigma-1}{\sigma}\right)^{\sigma}\left(\frac{\varphi}{c}\right)^{\sigma-1} \frac{D}{P}>0
\end{aligned}
$$

Formulas 6 and 7 show that the improvement of productivity and fixed cost input efficiency help improve the product quality of food enterprises. Fan et al. (2014) and Li (2014) show that 
industrial agglomeration can promote enterprise productivity, and enterprises with high productivity will increase the level of food quality through additional R\&D investment, so 有 $\frac{\partial \varphi}{\partial \mu}>0$ and $\frac{\partial \varepsilon}{\partial \mu}>0$ in the same manner. Therefore, we can deduce the relationship between industrial agglomeration and the food quality level, and the expression is as follows:

$\frac{\partial \lambda}{\partial \mu}=\frac{\partial \lambda}{\partial \varphi} \frac{\partial \varphi}{\partial \mu}>0 ; \frac{\partial \lambda}{\partial \mu}=\frac{\partial \lambda}{\partial \varepsilon} \frac{\partial \varepsilon}{\partial \mu}>0$

Formula 8 shows that industrial agglomeration can promote the improvement of food quality. Industrial agglomeration can effectively improve the productivity and fixed cost input efficiency of food enterprises and help promote the improvement of food quality.

\subsection{Analysis of the mechanism of industrial agglomeration and food quality}

Based on the theoretical framework of the previous section, it can be concluded that the external economies of scale resulting from industrial agglomeration affect the product quality of food enterprises through the two key determinants, namely, enterprise productivity and fixed cost input efficiency. This section will discuss how industrial agglomeration affects these two determinants and, thus, the product quality of food enterprises. Through the literature review, we can summarize the external economies of scale effects resulting from industrial agglomeration into three aspects: the talent agglomeration effect (human), the cost effect (financial) and the technology spillover effect (technology); that is, through the above agglomeration effects, the product quality of food enterprises is affected. The specific impact path is described below.

\section{Talent gathering effect}

The talent agglomeration effect involves the geographical agglomeration of enterprises in related industries, which is conducive to the formation of a specialized labor supply market and, thus, has an impact on the product quality of food enterprises. Industrial agglomeration is the external manifestation of productivity agglomeration. As an important factor of production, the spatial distribution of human capital depends on the spatial distribution of productivity (Sun \& You, 2008). Enterprises in related industries cluster in specific areas, which results in a high demand for talent with specific professional skills and, thus, many employment opportunities. Meanwhile, when the development of the enterprises in which they work is limited, specialized workers can choose to work in other enterprises in the cluster area. Thus, a talent pool appears in industrial agglomeration areas featuring more choices and opportunities; this phenomenon is called the talent gathering effect. First, enterprises can easily obtain the required talent in the cluster area according to their own needs, which expands the selection space for talent and helps restrain the output fluctuation caused by external shocks; additionally, both enterprises and talent are located in the cluster area, which reduces the degree of information asymmetry in the talent market and improves the matching degree and efficiency between enterprises and talent. The combination of the above two aspects promotes the improvement of enterprise productivity (Su et al., 2018). According to Formula 6, there is a positive correlation between enterprise productivity and the product quality of food enterprises. Therefore, in theory, the talent agglomeration effect can promote the product quality level of food enterprises.

\section{Cost effect}

The cost effect relates to the fact that industrial agglomeration helps reduce the cost of enterprises and, thus, has an impact on the product quality of food enterprises. First, the specialized division of labor and cooperation is close in the cluster area, and enterprises can obtain intermediate products more conveniently in the region, which can effectively reduce the production and transportation costs of enterprises (Xuan \& Xuan, 2012). Second, the public infrastructure in the agglomeration area can realize scale construction and utilization sharing, which can effectively reduce the cost of enterprise construction and use of infrastructure (Rosenthal \& Strange, 2004). Third, the relevant production factor market will be formed in or near the cluster area, which can effectively reduce the cost of obtaining production factors (Zhang \& Ma, 2004). For example, sharing a labor market can reduce the cost of recruiting and training employees; thus, information asymmetry among enterprises in the agglomeration area can be alleviated and effectively reduced. The transaction costs of enterprises are lowered because the enterprises are in a relatively close geographical area, which facilitates communication and cooperation between enterprises and increases trust. Although the reduction of production costs is conducive to improving the productivity of enterprises (Ellison et al., 2010), the reduction of fixed costs (e.g., information search costs and regulatory costs) will enable enterprises to have more funds for R\&D, increase the success probability of $\mathrm{R} \& \mathrm{D}$, and improve the efficiency of fixed cost investments (Ito et al., 2015). According to Formula 6 and Formula 7, productivity and fixed cost input efficiency are positively correlated with the product quality of food enterprises. Therefore, in theory, the technology spillover effect can promote the product quality level of food enterprises.

\section{Technology spillover effect}

The technology spillover effect involves the knowledge, information and technology spillover brought by enterprises' geographical proximity, which is conducive to the improvement of these firms' technology level and, thus, has an impact on the product quality of food enterprises. Spatial economics argues that the technology spillover effect will gradually decline with increasing distance, so the agglomeration of enterprises in a certain region is the basis for the existence of the technology spillover effect (Peng \& Jiang, 2011). The enterprises in the cluster area communicate and spread technological information through business cooperation (Capello, 1999), employee mobility (Rakesh, 2002) and informal contact and exchange among employees (Brown \& Duguid, 2000), which is called the technology spillover effect. Geographical agglomeration builds a scientific research cooperation platform for enterprises, creates a strong opportunity for talent and technology exchange among enterprises, allows knowledge and technology to effectively spread among 
enterprises, enhances the overall innovation ability of the cluster group, and promotes enterprise productivity (Head et al.,1995). However, the technology spillover caused by the geographical agglomeration of enterprises is conducive to reducing the complexity and uncertainty of technological innovation, reducing the cost of new product research and development, accelerating the technological progress of enterprises, improving the success rate of new product research and development, and improving the efficiency of fixed cost investment. According to Formula 6 and Formula 7, productivity and fixed cost input efficiency are positively correlated with the product quality of food enterprises. Therefore, in theory, the technology spillover effect can promote the product quality level of food enterprises.

In summary, this paper forms a research framework, as shown in Figure 1, which theoretically verifies the role of industrial agglomeration in promoting food quality improvement and shows that enterprise productivity and fixed cost input efficiency play a mediating role in the relationship between industrial agglomeration and the product quality of food enterprises; that is, industrial agglomeration affects the product quality improvement of food enterprises through enterprise productivity and fixed cost input efficiency. However, the ultimate impact of industrial agglomeration on the product quality of food enterprises needs to be strictly measured.

\section{Model setting, variable selection and data sources}

\subsection{Measurement model setting}

To investigate the impact of industrial agglomeration on the product quality improvement of food enterprises, the econometric model established based on the above theoretical framework and mechanism analysis is as follows (Formula 9):

$$
E S a f_{i t}=\alpha_{0}+\alpha_{1} A g g_{i t}+\beta \vec{M}+\mu_{i}+\mu_{t}+\varepsilon_{i t}
$$

where the subscripts $i$ and $t$ denote the enterprise and year, respectively; ESaf $f_{i t}$ is the explanatory variable in this paper, which represents the product quality level of dairy enterprises; $\mathrm{Agg}_{i t}$ is the core explanatory variable, which indicates industrial agglomeration; $\vec{M}$ is a group of control variables that affect food quality; $\alpha_{0}, \alpha_{1}$, and $\beta$ denote the parameter to be estimated or the parameter matrix; $\mu_{i}$ and $\mu_{t}$ are the fixed effects of region and year, respectively; and $\varepsilon_{i t}$ is a random perturbation term.

\subsection{Variable measurement}

Explained variable: food enterprise product quality $\left(E S a f_{i t}\right)$. In this paper, the unit price is used to measure product quality (Han \& Xu, 2014). As unit price data are difficult to obtain, this paper uses the unit price of raw materials as the proxy variable.

Explanatory variable: industrial agglomeration $\left(A g g_{i t}\right)$. Since the location entropy index is not affected by the regional scale, it can comprehensively reflect the spatial distribution of factors (Fan et al., 2014). Therefore, the methods presented in this study are consistent with the methods of existing scholars and include the use of location entropy to measure the level of food agglomeration. The specific formula is as follows (Formula 10):

$A_{g g_{i k h t}}=\frac{\left(W_{k h t}-W_{i k h t}\right) / W_{h t}}{W_{k t} / W_{t}}$

where $W_{i k h t}$ denotes the number of employees in year $t$ of enterprise I in industry h, $W_{k h t}$ denotes the number of manufacturing employees in industry $k$ of region h in year $t, w_{k t}$ is the number of employees in industry $k$ of China in year $t$, and $W_{t}$ is the number of manufacturing employees in the country in year $t$.

Control variables: (1) human capital $\left(H_{u m}\right)$. Human capital is the key factor affecting product quality (Schott, 2004). The knowledge-based labor force usually has a strong learning ability, which is helpful in improving product quality. This paper uses the per capita education expenditure of enterprise

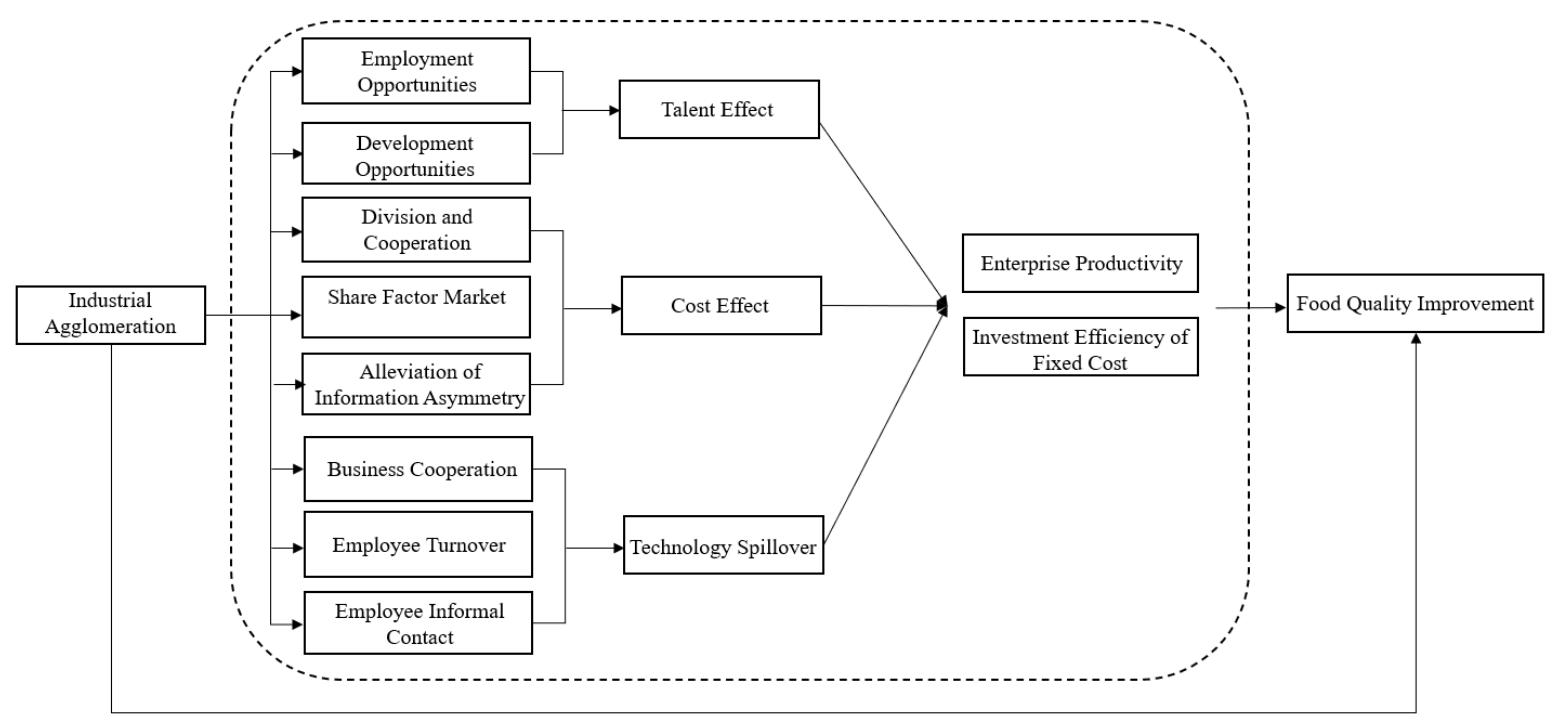

Figure 1. The framework of the mechanism by which industrial agglomeration affects food quality improvement. 
employees to measure human capital. (2) Capital intensity ( Cap $\left._{i t}\right)$. The level of physical capital has an impact on product quality (Falvey, 1981). The higher the enterprise capital intensity is, the more opportunities there are for the improvement of production technology and production levels, which promotes the improvement of product quality and food safety. This paper uses the per capita fixed capital stock of enterprises to measure capital intensity (Mao \& Fang, 2020). (3) Enterprise age $\left(A g e_{i t}\right)$. The longer an enterprise exists in the market, the more helpful it is to implement the learning curve effect and promote the improvement of product quality. However, the older the enterprise is in terms of the management system and business strategy, the more rigid and conservative it may be, inhibiting the improvement of product quality. This paper uses the enterprise survival time to measure enterprise age (Liu, 2015). (4) Enterprise size ( $\left.S c a_{i t}\right)$. Generally, large-scale enterprises have good conditions for improvement production technology, which is conducive to improving product quality. However, considering such conditions in China in general, there is still some low efficiency, and large-scale state-owned enterprises may reduce the promotion effect of the enterprise scale on product quality to a certain extent. This paper uses the annual average balance of the actual net fixed assets of enterprises to measure enterprise size. (5) Financing ability $\left(F_{i n}\right)$. Financing ability is an important factor that affects the product quality of enterprises (Zhang, 2015). The stronger the financing ability of an enterprise is, the lower the financing constraints it is subject to and the more conducive it is for the enterprise to implement long-term planning, carry out technological innovation, and improve its technical level and product quality. This paper uses the current ratio to measure financing ability (Zhang, 2015). (6) Government subsidies $\left(G_{i t}\right)$. In theory, a subsidy is equivalent to an increase in profits, which can expand investment, realize an internal scale economy and reduce unit costs. It can also lead to technological innovation, improve the technical level and improve product quality. However, if the government subsidy payment mechanism is not perfect, there may be adverse selection and moral hazard problems. Subsidized enterprises may not have the ability to innovate. Therefore, subsidies may not improve the technical level and product quality of enterprises. It is ideal to use the enterprise subsidy income to describe the variables. However, the observation value of the indicator in many samples is 0 . To ensure accuracy, this paper introduces a virtual variable for government subsidies. If the enterprise has subsidy income, this variable is assigned a value of 1 ; otherwise, it is assigned a value of 0 .

\subsection{Data sources and sample characteristics}

In recent years, China's food quality and safety problems have emerged in an endless stream, especially for dairy products, and have become the focus of public attention. Consumers' attention to dairy products has been increasing; therefore, dairy products were selected in this paper as an example for the empirical analysis, and matching data were selected from China's dairy industry yearbook and China's industrial enterprise database to analyze industrial agglomeration and the production of food enterprises. Empirical research on the quality of product relationships has been conducted. Considering the quality of the data and the accuracy of the calculation results, the author processed the variable data included in this paper as follows (Nie et al., 2012): (1) excluding the sample of enterprises with missing values; (2) excluding samples with fewer than 8 employees; (3) excluding samples with negative financial indicators, such as employee education expenses, fixed assets, depreciation, management expenses and industrial sale output values; (4) eliminating samples that obviously do not conform to accounting standards, such as those with a current asset value greater than the total asset value or a depreciation value for this year that is greater than the sample of accumulated depreciation value; and (5) excluding samples with the same enterprise name in the same year. After processing, the two sets of databases were matched according to the name of the enterprises. On this basis, 228 observations were obtained from the samples of enterprises in continuous operation in 2012 and 2013. Table 1 reports the descriptive statistical results for the main variables.

\section{Empirical analysis results}

\subsection{Benchmark regression and robustness tests}

This part establishes the panel data model. According to the Hausman test results, the original hypothesis of the random effects model is rejected at the $5 \%$ confidence level. Therefore, this paper reports the results for the fixed effects model. Because enterprises may have self-selection behavior, that is, enterprises producing high-quality dairy products will automatically choose to cluster in areas with a high net agglomeration effect, this reverse causality may overestimate the regression results. At the same time, some nonobservational factors may cause endogeneity problems. In this paper, instrumental variables are introduced into the model to further reduce the possible endogeneity problems. For this purpose, historical data on the number of county-level enterprises in 1995 were selected as the instrumental variable (Su et al., 2018), and the fixed effects model instrumental variable method was used to address the endogeneity problems of industrial agglomeration. Table 2 reports the benchmark regression results regarding the impact of industrial agglomeration on the product quality of dairy enterprises. Column (1) shows the estimation results of the fixed effects model (FE), and column (2) shows the estimation results of the fixed effects model with the instrumental variable method (FE-IV).

Table 1. Descriptive statistics for the main variables for dairy enterprises.

\begin{tabular}{ccccc}
\hline Variable & Mean & Std. Dev & Min & Max \\
\hline ESaf & 3.352 & 0.439 & 2.990 & 4.555 \\
Agg & 2.216 & 0.155 & 0.051 & 8.207 \\
Hum & 0.348 & 0.104 & 0.023 & 0.663 \\
Cap & 258.027 & 493.307 & 3.869 & 4215.739 \\
Age & 13.447 & 11.990 & 0.000 & 59.000 \\
Sca & 112.295 & 19.803 & 0.115 & 198.857 \\
Fin & 0.0113 & 0.337 & -1.518 & 0.671 \\
Gov & 0.259 & 0.438 & 0 & 1 \\
\hline
\end{tabular}

"Std. Dev" represents the standard deviation and reflects the degree of dispersion of the data set. 
Table 2. The benchmark measurement results regarding the industrial agglomeration and product quality of dairy enterprises.

\begin{tabular}{|c|c|c|}
\hline \multirow{2}{*}{ Explanatory variables } & \multicolumn{2}{|c|}{ Explained variables: ESaf } \\
\hline & $\mathrm{FE}$ & FE-IV \\
\hline \multirow[t]{2}{*}{ Agg } & $0.7476^{\star * *}$ & $0.8145^{* * *}$ \\
\hline & $(4.40)$ & $(5.01)$ \\
\hline \multirow[t]{2}{*}{ Hum } & $0.1810^{\star *}$ & $0.5351^{* *}$ \\
\hline & $(2.15)$ & $(2.26)$ \\
\hline \multirow[t]{2}{*}{ Cap } & $0.1171^{*}$ & 0.2529 \\
\hline & $(1.86)$ & $(1.27)$ \\
\hline \multirow[t]{2}{*}{ Age } & $0.8354^{* *}$ & $0.0595^{* *}$ \\
\hline & $(2.12)$ & $(1.98)$ \\
\hline \multirow[t]{2}{*}{ Sca } & 0.4972 & 0.0008 \\
\hline & $(0.51)$ & $(0.01)$ \\
\hline \multirow[t]{2}{*}{ Fin } & 0.2606 & 0.0186 \\
\hline & $(1.08)$ & $(0.94)$ \\
\hline \multirow[t]{2}{*}{ Gov } & $1.0090^{* * *}$ & $0.2963^{* *}$ \\
\hline & $(3.18)$ & $(2.49)$ \\
\hline \multirow[t]{2}{*}{ Cons } & $-0.0748^{* * *}$ & $-0.0781^{* * *}$ \\
\hline & $(-7.42)$ & $(-7.67)$ \\
\hline Ent & Yes & Yes \\
\hline Year & Yes & Yes \\
\hline$R^{2}$ & 0.3770 & 0.7317 \\
\hline$N$ & 228 & 228 \\
\hline
\end{tabular}

"FE" represents the fixed effects model; "FE-IV" represents the fixed effects model with the instrumental variable method; ${ }^{* *}$ Represent significance at the critical levels of $1 \%$; ${ }^{* *}$ Represent significance at the critical levels of $5 \%$; ${ }^{*}$ Represent significance at the critical levels of $10 \%$.

The results show that industrial agglomeration is an important factor in improving the product quality of dairy enterprises, which verifies the conclusion of the previous theoretical analysis framework. This positive effect may be a result of the external economies of scale brought about by industrial agglomeration. Geographically concentrated enterprises have a close division of labor and cooperation, which can be shared in infrastructure and the labor market. This scale effect is conducive to reducing enterprise costs and encouraging enterprises to invest more funds in product quality improvement control. However, enterprises have to pay more attention to product quality improvement. Being close to one another in a certain region is convenient for the express delivery of knowledge, technology and information; it is also convenient for informal and formal communication and exchange through employee flow and business cooperation, to realize knowledge spillover, to reduce the complexity and uncertainty of technological innovation, to accelerate the technological progress of enterprises, to promote enterprise product innovation, and, thus, to improve the level of product quality. From the perspective of the coefficient of the key explanatory variable, industrial agglomeration, the FE model with the instrumental variable method is better than the
FE model. Regarding whether "industrial agglomeration" is an endogenous variable, the Hausman test is used to test whether there are systematic differences between the two methods. The results show that the Hausman test significantly rejects the original hypothesis that there is no systematic difference, indicating that the model corresponding to Formula 9 has endogeneity problems. Therefore, the FE model with the instrumental variable method should be used. The parameter estimators are consistent, and the FE model's estimation results are biased. Therefore, the following articles are based on the FE model with the instrumental variable method.

By observing the estimation results for the control variables in Table 2, the variables of human capital, enterprise age and government subsidies meet the significance requirements, and the coefficients are all positive. The results first show that people with a strong learning ability can help enterprises improve technology and product quality more quickly, which is basically the same conclusion as that of existing literature on human capital and industrial quality. Second, the growth of enterprise age is conducive to the exertion of the enterprise experience curve effect and the improvement of the product quality level. Finally, government subsidies are conducive to the realization of an internal scale economy, thus reducing unit cost, and can also carry out technological innovation, improve the technical level, and improve the product quality level. The coefficients of other control variables are not significant, but they can still have an influence in the same direction. Symbols such as capital intensity, enterprise scale and financing capacity are consistent with expectations, which means that they play a positive role in promoting the product quality improvement of dairy enterprises.

With respect to industrial agglomeration measurement index selection, the number of employees is used in the measurement, and the industrial sales output value (Agg2) is used to further test the robustness. The estimation results in Table 3 show that there are no significant changes in the significance and numerical value of the core explanatory variables and control variables, indicating that the core conclusions of this chapter have not changed significantly due to different measurement methods of industrial agglomeration, which proves the robustness of the core conclusions.

\subsection{Heterogeneity analysis}

The previous analysis is based on the entire sample to investigate the relationship between industrial agglomeration and the product quality of dairy enterprises. Considering the possible heterogeneity of enterprises with respect to different characteristics and regions, this section will deeply explore the impact of industrial agglomeration on the product quality of dairy enterprises at two levels: enterprises and regions.

\section{Analysis of the heterogeneity of enterprises}

Since the reform and opening up, China has formed several specialized production and manufacturing industrial clusters, such as Kunshan electronics, Foshan ceramics, and Quanzhou luggage. These industrial clusters are mainly private and foreign-funded enterprises, which have a higher degree of 
Table 3. The measurement results of the robustness test of industrial agglomeration and product quality for dairy enterprises.

\begin{tabular}{|c|c|c|}
\hline \multirow{2}{*}{$\begin{array}{l}\text { Explanatory } \\
\text { variables }\end{array}$} & \multicolumn{2}{|c|}{ Explained variables: $E S a f$} \\
\hline & FE & FE-IV \\
\hline \multirow{2}{*}{$\operatorname{Agg} 2$} & $0.1994^{\star * *}$ & $0.3331^{* * *}$ \\
\hline & $(4.87)$ & $(7.16)$ \\
\hline \multirow{2}{*}{ Hum } & $0.0379^{*}$ & $0.2032^{* *}$ \\
\hline & $(1.78)$ & $(2.25)$ \\
\hline \multirow[t]{2}{*}{ Cap } & -0.0193 & -0.0093 \\
\hline & $(-0.76)$ & $(-0.28)$ \\
\hline \multirow[t]{2}{*}{ Age } & $0.1985^{* *}$ & $0.7143^{* * *}$ \\
\hline & $(2.10)$ & $(3.47)$ \\
\hline \multirow[t]{2}{*}{ Sca } & $0.037^{*}$ & 0.0129 \\
\hline & $(1.77)$ & $(0.50)$ \\
\hline \multirow{2}{*}{ Fin } & 0.0579 & 0.0535 \\
\hline & $(1.05)$ & $(1.20)$ \\
\hline \multirow[t]{2}{*}{ Gov } & $0.0729^{* * *}$ & $0.2006^{* * *}$ \\
\hline & $(2.67)$ & $(5.00)$ \\
\hline \multirow[t]{2}{*}{ Cons } & -0.0012 & -0.0605 \\
\hline & $(-0.42)$ & $(-0.23)$ \\
\hline Ent & Yes & Yes \\
\hline Year & Yes & Yes \\
\hline$R^{2}$ & 0.5564 & 0.4945 \\
\hline$N$ & 228 & 228 \\
\hline
\end{tabular}

${ }^{* * *}$ Represent significance at the critical levels of $1 \% ;{ }^{* *}$ Represent significance at the critical levels of $5 \%$; ${ }^{*}$ Represent significance at the critical levels of $10 \%$.

agglomeration. However, the location of state-owned enterprises is limited by government planning and strategic objectives, and the degree of enterprise agglomeration is relatively low. There are significant differences in the industrial layout among enterprises with different ownership systems in China, and dairy enterprises are no exception. Therefore, it is necessary to investigate the impact of industrial agglomeration on the product quality of dairy enterprises with different ownership systems. In this paper, dairy enterprises are divided into state-owned enterprises (NEs), private enterprises (PEs) and foreign-funded enterprises (AEs) according to their ownership type. Based on benchmark model (9), taking state-owned enterprises as the benchmark, the cross term of industrial agglomeration and ownership dummy variables is introduced. The regression results are shown in column (1) of Table 4 . The results show that the estimation coefficients of the cross items of the virtual variables of industrial agglomeration and PEs and those of industrial agglomeration and foreign-funded
Table 4. The measurement results of industrial agglomeration and product quality heterogeneity of dairy enterprises.

\begin{tabular}{|c|c|c|c|c|}
\hline \multirow{2}{*}{$\begin{array}{l}\text { Explanatory } \\
\text { variables }\end{array}$} & \multicolumn{4}{|c|}{ Explained variables: $E S a f$} \\
\hline & $\begin{array}{c}\text { Enterprise } \\
\text { heterogeneity }\end{array}$ & $\begin{array}{c}\text { Regional } \\
\text { heterogeneity }\end{array}$ & $\begin{array}{c}\text { Enterprise } \\
\text { heterogeneity }\end{array}$ & $\begin{array}{c}\text { Regional } \\
\text { heterogeneity }\end{array}$ \\
\hline \multirow{2}{*}{$A g g$} & $0.6874^{* * \star}$ & $0.9936^{* *+}$ & - & - \\
\hline & $(3.40)$ & $(3.09)$ & & \\
\hline \multirow[t]{2}{*}{$\operatorname{Agg} 2$} & - & - & $0.3773^{2+x+}$ & $0.3991^{* * *}$ \\
\hline & & & $(7.31)$ & $(7.10)$ \\
\hline \multirow[t]{2}{*}{$A g g \times \mathrm{PE}$} & $0.1937^{* *}$ & - & - & - \\
\hline & $(2.11)$ & & & \\
\hline \multirow[t]{2}{*}{$\operatorname{Agg} \times \mathrm{AE}$} & $0.0125^{*}$ & - & - & - \\
\hline & $(1.82)$ & & & \\
\hline \multirow[t]{2}{*}{$A g g \times$ East } & - & $3.354^{* *}$ & - & - \\
\hline & & $(2.07)$ & & \\
\hline \multirow[t]{2}{*}{$\operatorname{Agg} 2 \times \mathrm{PE}$} & - & - & $0.0108^{* *}$ & - \\
\hline & & & $(2.39)$ & \\
\hline \multirow[t]{2}{*}{$\operatorname{Agg} 2 \times \mathrm{AE}$} & - & - & $0.090^{*}$ & - \\
\hline & & & $(1.90)$ & \\
\hline \multirow[t]{2}{*}{$\operatorname{Agg} 2 \times$ East } & - & - & - & $0.3142^{* * *}$ \\
\hline & & & & $(4.16)$ \\
\hline Cont & Yes & Yes & Yes & Yes \\
\hline Ent & Yes & Yes & Yes & Yes \\
\hline Year & Yes & Yes & Yes & Yes \\
\hline \multirow[t]{2}{*}{ Cons } & -1.2104 & -0.0674 & $0.207^{* * *}$ & 0.0447 \\
\hline & $(-1.42)$ & $(-0.08)$ & $(5.83)$ & $(1.44)$ \\
\hline$R^{2}$ & 0.50 & 0.45 & 0.47 & 0.72 \\
\hline$N$ & 228 & 228 & 228 & 228 \\
\hline
\end{tabular}

${ }^{* * *}$ Represent significance at the critical levels of $1 \%$; ${ }^{* *}$ Represent significance at the critical levels of $5 \%$; ${ }^{*}$ Represent significance at the critical levels of $10 \%$.

enterprises are both positive and significant, indicating that the improvement of industrial agglomeration can promote the improvement of the product quality of non-state-owned dairy enterprises, and the estimation coefficient of the former is greater than that of the latter, indicating that the impact of industrial agglomeration on the product quality of private dairy enterprises is greater than that of the latter. The impact of industrial agglomeration on foreign-funded enterprises is greater than that of state-owned enterprises. The deep-seated reason for this may be that the location and layout of state-owned enterprises are mostly affected by the government's strategic objectives and planning and less affected by economic factors. Therefore, industrial agglomeration has little impact on their production and operational decisions, while the location and layout of non-state-owned enterprises are affected mainly by market factors, which is conducive to the development of the external scale economy of industrial clusters. Therefore, compared 
with state-owned dairy enterprises, industrial agglomeration plays a more important role in improving the product quality of private and foreign dairy enterprises.

\section{Analysis of the heterogeneity of regions}

Due to the influence of resource endowment, the economic foundation and government policies, the imbalance of regional economic development in China is particularly significant, and dairy industry agglomeration also shows obvious regional differences. Therefore, industrial agglomeration may also have a heterogeneous impact on the product quality of dairy enterprises in different regions. Therefore, the samples are divided into eastern, central and western regions. Based on benchmark model (9), taking the central and western regions as the benchmark, the cross term of industrial agglomeration and virtual variables for the eastern region is introduced. The specific regression results are shown in column (2) of Table 4. The results show that the effect of industrial agglomeration on improving the product quality of dairy enterprises in the eastern region is greater than that in the central and western regions. The deep-seated reason for this finding may be that the eastern region, as the main production and processing industry cluster area, has a good agglomeration development foundation, has formed a good communication and learning atmosphere among enterprises, has more frequent interactions, and experiences a more significant economic effect of agglomeration.

As before, this part uses ${ }^{A g g} 2$ as an alternative index to perform further robustness tests. The results in columns (3) and (4) of Table 4 show the robustness of the conclusions in this section.

\section{Empirical verification of the action mechanism}

The empirical regression results show that the improvement of the degree of industrial agglomeration can promote the improvement of the product quality level of dairy enterprises. Thus, research on the mechanism by which industrial agglomeration improves the product quality of dairy enterprises will help us further study the internal relationship between them. The previous theoretical analysis shows that industrial agglomeration affects the product quality of dairy enterprises through enterprise productivity and fixed cost input efficiency. Therefore, this aspect of the mechanism validation will select enterprise productivity and fixed cost input efficiency as the intermediary variables by constructing the intermediary effect model to verify the transmission path by which industrial agglomeration affects the quality of dairy products through enterprise productivity and fixed cost input efficiency.

\subsection{Mediating effect model setting}

The above analysis shows that enterprise productivity and fixed cost input efficiency have an impact on the product quality of dairy enterprises, and industrial agglomeration also affects enterprise productivity and fixed cost input efficiency. Based on these findings, this part infers that industrial agglomeration may indirectly affect dairy product quality through enterprise productivity and fixed cost input efficiency; that is, enterprise productivity and fixed cost input efficiency are intermediary variables. This part uses the general model of the mediating effect to establish the econometric model (Baron \& Kenny, 1986; Wen \& Ye, 2014) and tests the mechanism by which industrial agglomeration affects the product quality of dairy enterprises through the intermediary variables of enterprise productivity and fixed cost input efficiency.

$$
\begin{aligned}
& \operatorname{ESaf}_{i t}=\partial_{0}+\partial_{1} \operatorname{Agg}_{i t}+\rho \vec{M}+\mu_{i}+\mu_{t}+\varepsilon_{i t} \\
& T f p_{i t}=\gamma_{0}+\gamma_{1} \operatorname{Agg}_{i t}+\pi \vec{M}+\mu_{i}+\mu_{t}+\varepsilon_{i t} \\
& \operatorname{Car}_{i t}=\vartheta_{0}+\vartheta_{1} \operatorname{Agg}_{i t}+\omega \vec{M}+\mu_{i}+\mu_{t}+\varepsilon_{i t} \\
& \operatorname{ESaf}_{i t}=\delta_{0}+\delta_{1} \operatorname{Agg}_{i t}+\delta_{2} T f p_{i t}+\delta_{3} \operatorname{Car}_{i t}+\varphi \vec{M}+\mu_{i}+\mu_{t}+\varepsilon_{i t}
\end{aligned}
$$

In Equation 11, the explained variable represents the quality and safety level of dairy products. In Equation 12, the explained variable $T f p_{i t}$ represents the firm's productivity. In Formula 13, the explained variable $\mathrm{Car}_{i t}$ represents the fixed cost input efficiency. The remaining variables are consistent with the previous variables. $\partial_{0}-\partial_{1}$ and $\gamma_{0}-\gamma_{1}, \vartheta_{0}-\vartheta_{1}, \delta_{0}-\delta_{3}, \rho, \pi, \omega$, and $\varphi$ are the parameter or parameter matrices to be estimated; $\mu_{i}$ and $\mu_{t}$ are the FE for region and year, respectively; and $\varepsilon_{i t}$ is a random disturbance term.

The above variables will not be repeated here. This section only briefly describes the selection and measurement of the two intermediary variables.

$T f p_{i t}$ is enterprise productivity, measured by total factor productivity. According to the research of Lu \& Lian (2012), the OLS method has sample selection bias and simultaneity deviation, and the FE method applies only to balanced panel data and has endogeneity problems. The OP rule needs to use enterprise investment as a proxy variable, but this variable is largely missing from the industrial enterprise database; therefore, the Levinsohn \& Petrin (2003) (LP) semiparametric estimation method is used to measure the total factor productivity of enterprises. This method can not only effectively solve the endogeneity problem but also solve the problem that proxy variables in the OP method cannot fully respond to changes in enterprise productivity (Gong \& Hu, 2013).

$\mathrm{Car}_{i t}$ is the fixed cost input efficiency. Existing scholars mostly use enterprise R\&D efficiency to describe fixed cost input efficiency (Thomas et al., 2011) or the proportion of intangible assets among the total assets (Su et al., 2018), but there is a lack of data related to research and development related to the original data. To ensure a sufficient sample size and data accuracy, this paper uses the fixed assets input-output ratio to measure the variable. The calculation formula is fixed assets input-output ratio $=$ the annual average balance of fixed assets net value/ industrial added value (Zhan, 2019).

\subsection{Empirical test results for the action mechanism}

Table 5 reports the estimated results for the interaction mechanism between industrial agglomeration and product quality improvement of dairy enterprises. Column (1) shows the estimation results of the benchmark model, which is the same as that shown in column (2) of Table 2; column (2) and column 
Table 5. The test results of action mechanism.

\begin{tabular}{|c|c|c|c|c|c|c|}
\hline & ESaf & $T f p$ & Car & ESaf & ESaf & ESaf \\
\hline & (1) & (2) & (3) & (4) & (5) & (6) \\
\hline Agg & $\begin{array}{c}0.8145^{\star * *} \\
(5.01)\end{array}$ & $\begin{array}{c}0.7087^{* * *} \\
(3.51)\end{array}$ & $\begin{array}{c}0.5161^{* * *} \\
(3.90)\end{array}$ & $\begin{array}{c}0.2510^{* * *} \\
(2.79)\end{array}$ & $\begin{array}{c}0.0560^{* *} \\
(2.15)\end{array}$ & $\begin{array}{c}0.0333^{*} \\
(1.82)\end{array}$ \\
\hline$T f p$ & $\begin{array}{l}- \\
-\end{array}$ & $\begin{array}{l}- \\
-\end{array}$ & $\begin{array}{l}- \\
-\end{array}$ & $\begin{array}{c}0.0427^{\star * *} \\
(3.30)\end{array}$ & $\begin{array}{l}- \\
-\end{array}$ & $\begin{array}{c}0.0334^{* * *} \\
(3.80)\end{array}$ \\
\hline Car & - & - & - & - & $\begin{array}{c}0.9259^{* * *} \\
(3.28)\end{array}$ & $\begin{array}{c}0.5482^{* * *} \\
(3.26)\end{array}$ \\
\hline Cont & Yes & Yes & Yes & Yes & Yes & Yes \\
\hline Ent & Yes & Yes & Yes & Yes & Yes & Yes \\
\hline Year & Yes & Yes & Yes & Yes & Yes & Yes \\
\hline Cons & $\begin{array}{c}-0.0781^{* * *} \\
(-7.67)\end{array}$ & $\begin{array}{c}-2.0933 \\
(-0.97)\end{array}$ & $\begin{array}{l}-0.0203 \\
(-1.25)\end{array}$ & $\begin{array}{c}0.3657^{* * *} \\
(3.87)\end{array}$ & $\begin{array}{r}0.0478 \\
(0.16)\end{array}$ & $\begin{array}{c}0.0242 \\
(0.85)\end{array}$ \\
\hline$R 2$ & 0.7317 & 0.7984 & 0.7200 & 0.7889 & 0.7605 & 0.7782 \\
\hline$N$ & 228 & 228 & 228 & 228 & 228 & 228 \\
\hline
\end{tabular}

(3) show the regressions of industrial agglomeration and enterprise productivity and fixed cost input efficiency, respectively, to test the relationship between them. The results show that there is a significant positive correlation between industrial agglomeration and enterprise productivity and fixed cost input efficiency. The results show that industrial agglomeration can promote the productivity and fixed cost input efficiency of enterprises. Columns (4) to (6) further report the regression of the explained variables on the core explanatory variables and intermediary variables, i.e., the regression results for Formula 14. The results show that the two mediating variables of the enterprise production rate and fixed cost input efficiency can promote the improvement of dairy product quality, and the effect is consistent with expectations. It is also found that after adding the intermediate variables of enterprise productivity (column (4)) and fixed cost input efficiency (column (5)), the estimated coefficient of industrial agglomeration decreases in both significance and value compared with column (1), which preliminarily shows the existence of an intermediary effect of the two medium variables. In future studies, after enterprise productivity and fixed cost input efficiency are added to the model, the estimation coefficient of industrial agglomeration further decreases in significance and value, which indicates that enterprise productivity and fixed cost input efficiency are important mechanisms for industrial agglomeration to improve the product quality level of dairy enterprises. The above empirical tests confirm that industrial agglomeration can affect the product quality level of dairy enterprises through two factors: enterprise productivity and fixed cost input efficiency, and the external economies of scale brought by industrial agglomeration can promote the product quality improvement of dairy enterprises.

\section{Conclusion and discussion}

China's food industry is in a critical period of transformation from the high-speed growth stage to the high-quality development stage. Improving food quality and ensuring food safety are top priorities in promoting the transformation and improvement of the food industry. Although the development of China's food industry has made outstanding achievements, China's food industry is small, scattered and weak, leading to the lack of industry quality assurance ability. Therefore, it is very important to explore the external driving force of food quality improvement to ensure the healthy and sustainable development of the food industry. Based on the above background, this paper systematically discusses the impact and mechanism of industrial agglomeration representing a localized production system on the product quality of food enterprises. Taking dairy industry data as an example, this paper utilized the data on China's industrial enterprises and China's dairy industry yearbook for empirical testing. The results show that (1) industrial agglomeration significantly improves the product quality of China's food enterprises, which means that in general, the agglomeration effect produced by industrial agglomeration is greater than the excessive competition effect resulting from industrial agglomeration; after the index transformation, the core explanatory variables and control variables do not change significantly under the numerical value and significance level, which proves the core conclusion of robustness. (2) The results of the heterogeneity analysis show that industrial agglomeration plays a greater role in promoting the product quality of non-state-owned food enterprises than that of state-owned food enterprises; additionally, industrial agglomeration plays a greater role in promoting the product quality of food enterprises in the eastern region than in the central and western regions. (3) The mechanism test results show that industrial agglomeration has an impact on food quality improvement, and there is a mediating effect; that is, enterprise productivity and enterprise fixed cost input efficiency are important mechanisms for industrial agglomeration to improve the product quality of food enterprises.

In general, this study confirms that industrial agglomeration can be used as an external driving force for China's food quality improvement. Based on the small-scale and decentralized characteristics of China's food industry, the role of the market mechanism, and the macro policy of industrial agglomeration, promoting the external scale economic effect of agglomeration has the following important policy implications for generating a high-quality food industry. (1) It strengthens the education and training of employees in food enterprises. Education and training in food nutrition and health, food safety, food laws and regulations should be carried out for employees of food enterprises to improve their personal quality and professional ability, engage them in food quality work, and improve the average level of specialized technology of the labor market in the cluster area. (2) It enables food quality information exchange and early risk warning. Scientific research cooperation platforms should be built among the government, industry and enterprises within the enterprise and the cluster area, regular formal and informal information communication and exchange mechanisms should be established, information communication and exchange within the industry should be promoted, and the overall innovation ability of enterprises in the cluster area should be enhanced; additionally, problems should be discovered, quality risks investigated, and early quality risk warnings realized. (3) It improves relevant industrial policies and establishes incentive mechanisms. The empirical results show that government subsidies can help improve product quality. Therefore, food enterprises producing high-quality products should be given incentive subsidies or preferential tax and financial policies; this will encourage food enterprises to further improve their product quality and achieve a higher level of food safety. 


\section{Acknowledgements}

We gratefully acknowledge the financial support from National Natural Science Foundation of China (Grant No. 91746202; 71433006; 71373117)

\section{References}

Baron, R. M., \& Kenny, D. A. (1986). The moderator-mediator variable distinction in social psychological research: conceptual, strategic, and statistical considerations. Journal of Personality and Social Psychology, 51(6), 1173-1182. http://dx.doi.org/10.1037/00223514.51.6.1173 PMid:3806354.

Brown, J. S., \& Duguid, P. (2000). Mysteries of the region: knowledge dynamics in Silicon Valley. In: C. Lee, W.G. Miller, M.G. Hancock \& H.S. Rowen (Eds.), The Silicon Valley edge: a habitat for innovation and entrepreneurship (pp. 16-39). Stanford, CA: Stanford University Press.

Capello, R. (1999). Spatial transfer of knowledge in high technology milieu: learning versus collective learning process. Regional Studies, 33(4), 353-365. http://dx.doi.org/10.1080/00343409950081211.

Ellison, G., Glaeser, E., \& Kerr, W. R. (2010). What Causes Industry Agglomeration? Evidence from Coagglomeration Patterns. American Economic Review, 100(3) ,1195-1213.

Falvey, R. E. (1981). Commercial policy and intra-industry trade. Journal of International Economics, 11(4), 495-511. http://dx.doi. org/10.1016/0022-1996(81)90031-3.

Fan, J.Y., Feng, M., \& Li, F. W. (2014). Industrial agglomeration and total factor productivity. The Journal of World Economy, 5, 51-73.

Gervais, A. (2015). Product quality, firm heterogeneity and international trade. The Canadian Journal of Economics, 48(3), 1152-1174. http:// dx.doi.org/10.1111/caje.12171.

Gong, G., \& Hu, G. L. (2013). Resource allocation efficiency and total factor productivity of China's manufacturing industry. Economic Research Journal, 48(4), 4-15.

Hallak, J., \& Sivadasan, J. (2008). Productivity, quality and exporting behavior under minimum quality requirements. Michigan: University of Michigan.

Han, H., \& Xu, K.N. (2014). Hypothesis and test of "quality threshold" of chinese product export. China Industrial Economics, 4, 58-70.

Head, K., Ries, J., \& Swenson, D. (1995). Swenson D. agglomeration benefits and location choice: evidence from japanese manufacturing investments in the United States. Journal of International Economics, 38(3-4), 223-247. http://dx.doi.org/10.1016/0022-1996(94)01351-R.

Ito, B., Xu, Z. Y., \& Yashiro, N. (2015). Does agglomeration promote internationalization of chinese firms. China Economic Review, 34(7), 109-121. http://dx.doi.org/10.1016/j.chieco.2015.03.009.

Khandelwal, A. K., Schott, P. K., \& Wei, S. J. (2013). Trade liberalization and embedded institutional reform: evidence from chinese exporters. The American Economic Review, 103(6), 2169-2195. http://dx.doi. org/10.1257/aer.103.6.2169.

Levinsohn, J., \& Petrin, A. (2003). Estimating production functions using inputs to control unobservables. The Review of Economic Studies, 70(2), 317-341. http://dx.doi.org/10.1111/1467-937X.00246.

Li, F.J. (2014). Enterprise productivity, product quality and export destination selection: evidence from the micro level of chinese manufacturing enterprises. Contemporary Finance and Economics, 4, 86-97.

Liu, H. D., Chen, H., \& Li, W. Y. (2016). Research on the impact of industrial agglomeration on the quality of export products: an empirical analysis based on china's provincial panel data. Contemporary Economic Research, 7, 84-91.
Liu, X. N. (2015). Research on trade liberalization, heterogeneous enterprises' export decision-making and export product quality upgrading. China: Shandong University.

Lu, X. D., Lian, Y. J. (2012). Estimation of Total Factor Productivity of Chinese Industrial Enterprises: 1999-2007. China Economic Quarterly, 11(2), 541-558.

Mao, Q. L., \& Fang, S. H. (2020). How FDI liberalization affects China’s manufacturing productivity. Japan and the World Economy, 43(1), 143-169.

Melo, P. C., Graham, D. J., \& Noland, R. B (2009). A Meta -analysis of Estimates of Urban Agglomeration Economies. Regional Science and Urban Economics, 39(3), 332-342.

Nie, H. H., Jiang, C., \& Yang, R. D. (2012). The current situation and potential problems of China's industrial enterprise database. World Economy, 35(5), 142-158.

Peng, X., \& Jiang, C. H. (2011). Industrial agglomeration, knowledge spillover and regional innovation: an empirical test based on china's industrial industry. China Economic Quarterly, 10(3), 913-934.

Rakesh, B. (2002). Knowledge flows and industrial clusters: an analytical review of literature. East-west Center, Working Paper, 40, 11-12.

Rosenthal, S. S., \& Strange, W. C. (2004). Evidence on the nature and sources of agglomeration economies. In J.V. Henderson \& J. F. Thsse (Eds.), Handbook of regional and urban economics (vol. 4, pp. 21192171). Amsterdam: Elsevier.

Schott, P. K. (2004). Across-product versus within-product specialization in international trade. The Quarterly Journal of Economics, 119(2), 646-677. http://dx.doi.org/10.1162/0033553041382201.

Su, D.N., Sheng, B., Shao, C.D (2018). Industrial Agglomeration and Quality Upgrading of Export Products. China Industrial Economics, 11, 117-135.

Sun, J., \& You, W. (2008). Research on the interaction between talent agglomeration and industrial agglomeration. Management World, 3, $177-178$.

Thomas, V. J., Sharma, S., \& Jain, S. K. (2011). Using patents and publications to assess R\&D efficiency in the states of the USA. World Patent Information, 33(1), 4-10. http://dx.doi.org/10.1016/j. wpi.2010.01.005.

Wen, Z., \& Ye, B. (2014). Analyses of mediating effects: the development of methods and models. Xinli Kexue Jinzhan, 22(5), 731-745. http:// dx.doi.org/10.3724/SP.J.1042.2014.00731.

World Health Organization - WHO. (2002). Food safety and food-bome illness. Geneva: World Health Organization.

Xuan, Y., \& Xuan, S. Y. (2012). An empirical study on industrial agglomeration, technological innovation and export of high-tech enterprises. Journal of International Trade, 5, 136-146.

Yapp, C., \& Fairman, R. (2006). Factors affecting food safety compliance within small and medium -sized enterprises: Implications for regulatory and enforcement strategies. Food Control, 17(1), 42-51. http://dx.doi.org/10.1016/j.foodcont.2004.08.007.

Zhan, M. H. (2019). Analysis of the quality of China's export products and its influencing factors. China: Zhejiang University of Technology.

Zhang, A. M., Zhang, Y. M., \& Zhao, R. (2003). A study of the R\&D efficiency and productivity of chinese firms. Journal of Comparative Economics, 31(3), 444-464. http://dx.doi.org/10.1016/S01475967(03)00055-6.

Zhang, J. (2015). Financial depression, financing constraint and export product quality. Journal of Financial Research, 6, 64-79.

Zhang, Y. Z., \& Ma, M. X. (2004). Enterprise scale, scale economy and industrial cluster. China Industrial Economics, 6, 29-35.

Zhong, Z., \& Chen, S. F. (2014). Production cost, scale economy and quality and safety of agricultural products - scale economy analysis based on quality and safety of fresh milk. China Rural Economy, $1,49-61$. 